\title{
Prevalence of fibromyalgia in a low socioeconomic status population
}

\author{
Ana Assumpção*1, Alane B Cavalcante ${ }^{2}$, Cristina E Capela ${ }^{3}$, Juliana F Sauer ${ }^{2}$, \\ Suellen D Chalot ${ }^{2}$, Carlos AB Pereira ${ }^{4}$ and Amélia P Marques ${ }^{2}$
}

Address: ${ }^{1}$ Experimental Physiopathology Post Graduating Program, School of Medicine, University of São Paulo, São Paulo, Brazil, ${ }^{2}$ Department of Physical, Speech, and Occupational Therapy, School of Medicine, University of São Paulo, São Paulo, Brazil, ${ }^{3}$ Department of Physical Therapy, Universidade Bandeirantes, São Paulo, Brazil and ${ }^{4}$ Statistics Department, Institute of Mathematics and Statistics, University of São Paulo, São Paulo, Brazil

Email: Ana Assumpção* - anassumpcao@usp.br; Alane B Cavalcante - alanebc@gmail.com; Cristina E Capela - criscapela@terra.com.br; Juliana F Sauer - juliana.sauer@gmail.com; Suellen D Chalot - ischalot@uol.com.br; Carlos AB Pereira - cpereira@ime.usp.br; Amélia P Marques - pasqual@usp.br

* Corresponding author

Published: 8 June 2009

BMC Musculoskeletal Disorders 2009, 10:64 doi:10.1186/147I-2474-10-64
Received: 2 November 2008

Accepted: 8 June 2009

This article is available from: http://www.biomedcentral.com/I47I-2474/10/64

(c) 2009 Assumpção et al; licensee BioMed Central Ltd.

This is an Open Access article distributed under the terms of the Creative Commons Attribution License (http://creativecommons.org/licenses/by/2.0), which permits unrestricted use, distribution, and reproduction in any medium, provided the original work is properly cited.

\begin{abstract}
Background: The aim of this study was to estimate the prevalence of fibromyalgia, as well as to assess the major symptoms of this syndrome in an adult, low socioeconomic status population assisted by the primary health care system in a city in Brazil.

Methods: We cross-sectionally sampled individuals assisted by the public primary health care system $(n=768,35-60$ years old). Participants were interviewed by phone and screened about pain. They were then invited to be clinically assessed (304 accepted). Pain was estimated using a Visual Analogue Scale (VAS). Fibromyalgia was assessed using the Fibromyalgia Impact Questionnaire (FIQ), as well as screening for tender points using dolorimetry. Statistical analyses included Bayesian Statistics and the Kruskal-Wallis Anova test (significance level $=5 \%$ ).

Results: From the phone-interview screening, we divided participants $(n=768)$ in three groups: No Pain (NP) ( $n=185)$; Regional Pain (RP) $(n=388)$ and Widespread Pain (WP) $(n=106)$. Among those participating in the clinical assessments, (304 subjects), the prevalence of fibromyalgia was $4.4 \%$ ( $95 \%$ confidence interval $[2.6 \% ; 6.3 \%]$ ). Symptoms of pain (VAS and FIQ), feeling well, job ability, fatigue, morning tiredness, stiffness, anxiety and depression were statically different among the groups. In multivariate analyses we found that individuals with FM and WP had significantly higher impairment than those with RP and NP. FM and WP were similarly disabling. Similarly, RP was no significantly different than NP.
\end{abstract}

Conclusion: Fibromyalgia is prevalent in the low socioeconomic status population assisted by the public primary health care system. Prevalence was similar to other studies (4.4\%) in a more diverse socioeconomic population. Individuals with FM and WP have significant impact in their well being. 


\section{Background}

Fibromyalgia (FM) is a frequent rheumatologic disorder worldwide [1-5]. It responds by up of $7 \%$ of all primary care consultations, imposing substantial costs to the system [6].

The prevalence of FM ranges from $0.66 \%$ to $10.5 \%$ [7], with most studies pointing into a prevalence around $2 \%$ in the adult population. Prevalence is higher in women (around 3.4\%) [8] and in middle-age (5\%) [1,4]. Most studies were conducted in developed countries; studies in emerging countries or in under-assisted populations are scarce.

Although the impact of FM in productivity $[9,10]$, disability $[11,12]$ and quality of life $[13,14]$ of sufferers is well documented in the Brazilian population [14,15], only one study assessed its prevalence. This study was conducted in a single city and reported a prevalence of $2.5 \%$ [4]. Because Brazil is a continental country, other studies are necessary. A better understanding of the epidemiology of FM is an important step for planning the health care system to properly assist this population, assuring improvements in the quality of care and rational costimplementation.

The aim of this study was to estimate the prevalence of FM and its symptoms in a middle-aged adult population (3560 years) registered in the primary health care system of a city in Brazil (Embu City, São Paulo State). The population assisted by this system is of low income. We hypothesized that the prevalence of FM is increased in this low income population, may be because they are exposed to several pain risk factors.

\section{Methods \\ Sample}

Our study was conducted in Embu, in the metropolitan area of São Paulo, Brazil. We chose this city because it has similar socio-demographic characteristics of São Paulo city and of other cities in the area. The city has an area of $70 \mathrm{~km}^{2}$, with a population of 207,663 inhabitants. Most of its population is of low income as per estimates of Gross Domestic Income (GDI - per capita GDI is 3,000 dollars). The Human Development Index (HDI) is 0.772; $7.7 \%$ of the adult population is illiterate; overall, mean number of school years is 6.5 [16].

Our sample was non-probabilistic; potential participants were selected from the nine units that form the first access to public primary health care system, from the Brazilian Unified Health System, in the city [16]. For individuals of low-income, the Unified Health System is basically the only option for health care, also granting access to other forms of governmental support. For Embu population, the public health care represents $77 \%$ of all health establishments in the city [16].

\section{Procedures and Methods}

For the screening survey, we selected all individuals registered in the nine primary care units during the year of 2003. Potential participants were 35-60 years in the year of 2004. In a pilot study we found difficult to conduct face-to-face interviews with these individuals. Because $73 \%$ of the 3,109 registered subjects had telephone at the time of the survey, we conducted the screening interviews by phone.

We attempted to contact all 2,269 potential participants. Around $30 \%$ of them could not be contacted because were not available, even though the calls were done more than once for each household, and at different times of the day. The refuse rate was insignificant $(>1 \%)$. Because our sample size was estimated as being less than 768 , we ended this screening phase.

The screening phone interviews were conducted by trained staff (three physical therapists and three students of physical therapy). They assessed the presence of pain (yes/no), time of pain (in months), and pain distribution (which sites of pain). The screening survey intended to triage individuals with pain as it is typically done in studies of this nature.

According to the American College of Rheumatology criteria (ACR), respondents were classified as suffering from widespread pain (WP) when they had pain in the "axial + upper and lower segment + left and right-sided pain" [17]. Those without WP were classified as having regional pain (RP - pain not fulfilling the WP criteria) or no pain (NP). The majority of subjects with pain $(92 \%)$ had it for more then three months (chronic pain) (Figure 1).

All 768 respondents were invited to participate in a clinical interview, where they would be assessed using standardized questionnaires and exams of potential tender points. Of them, 304 accepted and were seen in one of the participant's primary care units. The volunteers did not receive any financial support.

In the evaluation, we obtained socio-demographic data, as well as pain history. Pain intensity was measured with the Visual Analogue Scale (VAS). Tender points were assessed using the Fischer dolorimeter [18], according to the ACR [17] and Okifuji et al. [19]. Tender points were defined positive if tenderness was present at $2.6 \mathrm{~kg} / \mathrm{cm}^{2}$ of pressure [20]. Tests were performed by an experienced physical therapist. Although the ACR criteria recommend manual pressure for determining tender points, the reliability of this method is questionable $[21,22]$, and assess- 


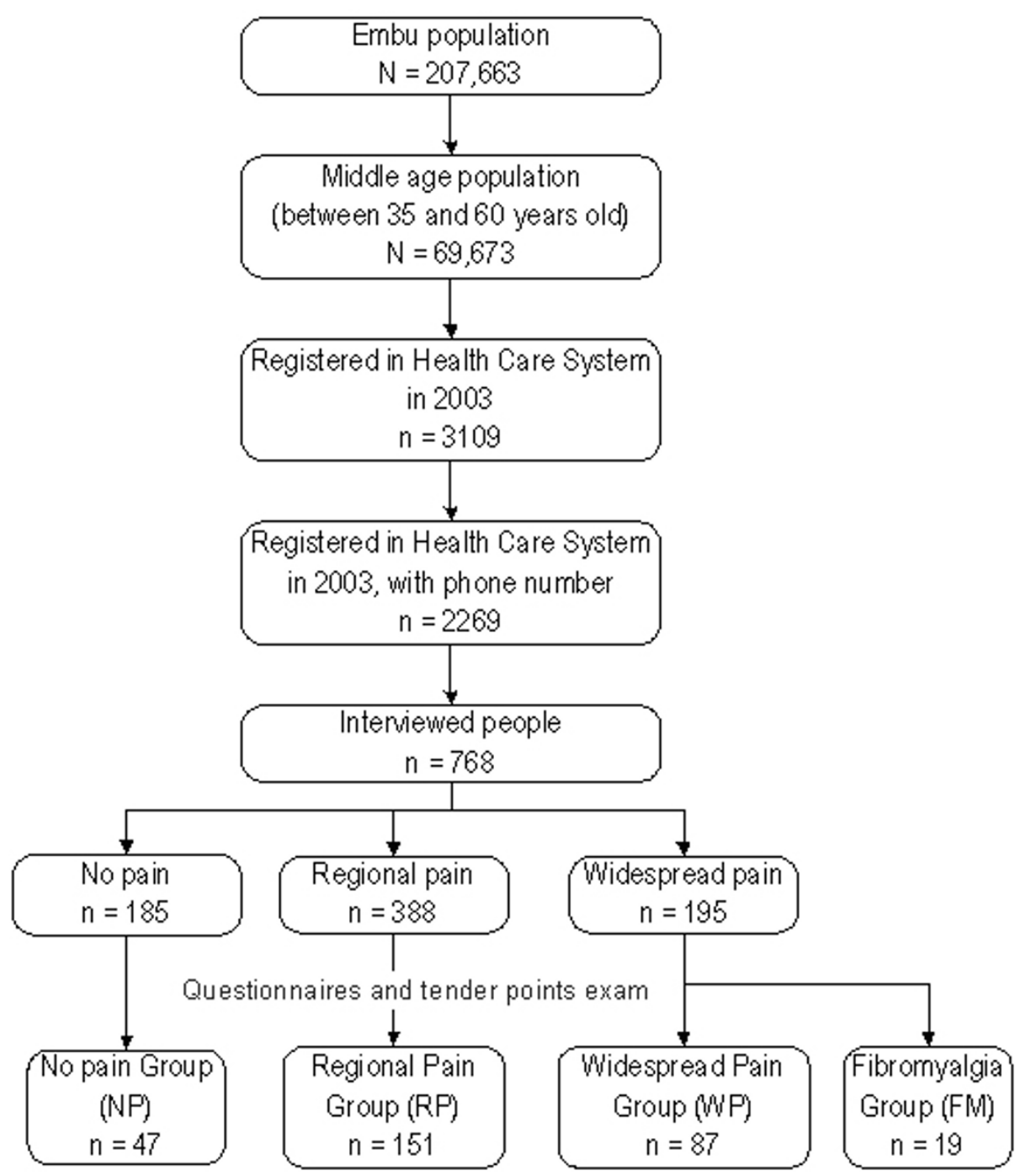

\section{Figure I}

\section{Flow chart for inclusion procedure and distribution of subjects among groups.}

ments of pain threshold by dolorimeters have been suggested [21].

Major FM symptoms were assessed by the Fibromyalgia Impact Questionnaire (FIQ) [23], which has been validated for Brazilian Portuguese [24]. Because of the high proportion of individuals with low education, the questions were supervised by a researcher.

The screening algorithm for the diagnosis of FM considered the presence and number of tender points and the pain features, as proposed by the ACR (Figure 1).

This study was reviewed and approved by the local Ethics Committee and informed consent was obtained.

\section{Data Analysis}

The data were coded using Excel for Windows (version 2002) and Analyze-it (version 2000), MINITAB 14, SAS System V8 and Statistica V7.

The prevalence of FM was estimated based on Bayesian Analysis. By using this method, phone interviews could be used to estimate the prevalence of widespread chronic pain. Furthermore, this analysis better address several of the biases in clinical research, allowing the use of a bigger sample $(\mathrm{n}=768)$ in many of the estimates [25].

Data obtained from the FIQ were tested for normality using the Shapiro-Wilk test. Groups were compared using the Kruskal-Wallis Anova and multiple variance analysis. The significance level was 0.05 . 


\section{Results}

Most of the 768 subjects participating in the screening phone interview were women $(77 \%)$, married and of low educational level. Table 1 presents demographic data for participants in the phone and clinical assessments.

Using the Bayesian approach, the prevalence of widespread chronic pain was $24 \%$, with a $95 \%$ credibility interval (CI) [21\%; 27\%]. Among individuals with WP the prevalence of FM was $18 \%(95 \% \mathrm{CI}=11 \%-25 \%)$. For this calculation, the Beta distribution parameters were 0.1 to 0.4 (a priori) and 19.1 to 87.4 (a posteriori). The beta distribution assumes continuous.. probability distributions defined on the interval $[0,1]$. The a priori parameters was defined based on known proportions of WP and FM and the a posteriori parameters was calculated based on the number of FM and WP subjects. Accordingly, the prevalence of FM was defined as a function of WP probability and proportion of individuals with WP who also endorsed FM. It was 4.4\% (95\% CI = 2.7\%-6.3\%).

\section{Fibromyalgia symptoms}

The items of the FIQ questionnaire were significantly different among the groups, except for physical function and work missed. Individuals with FM were the most impaired. However, in multiple variance analysis, FM and
WP were similar, and significantly different than RP and NP.

Individuals with NP had significantly less impairment, as compared to the other groups, in several domains including working for job ability, pain, fatigue, morning tiredness, stiffness and depression. Individuals with RP were less impaired than WP in the domains of well, fatigue, morning tiredness and anxiety, and different from FM for fatigue and stiffness. Individuals with WP and FM had no significant differences in the assessed domains in multiple variances analysis. Pain, as assessed by the VAS, was significantly higher in the FM group, followed by in those with WP (p < 0,001) (Table 2).

\section{Discussion}

In our study, the prevalence of FM in a middle-aged adult population of a low socioeconomic population was $4.4 \%$ and all cases were women. The prevalence was higher than what has been reported elsewhere. In most studies the prevalence ranges from $2 \%$ to $4 \%[8,13]$, but important discrepancies exist [26-28].

The high prevalence of FM found in our study may be explained by the age of our inclusion sample (35 - 60 years old), when fibromyalgia is more frequent, as shown

Table I: Demographic data of participants in the phone interview $(n=788)$ and on the in-person assessments $(n=304)$.

\begin{tabular}{|c|c|c|c|c|}
\hline Phone Interview & $\begin{array}{l}\text { No Pain } \\
(n=185)\end{array}$ & $\begin{array}{c}\text { Regional pain } \\
(n=388)\end{array}$ & $\begin{array}{l}\text { Widespread pain } \\
\quad(n=195)\end{array}$ & \\
\hline \multicolumn{5}{|l|}{ Gender } \\
\hline Female & $123(66 \%)$ & 294 (76\%) & $173(88 \%)$ & \\
\hline Male & $62(34 \%)$ & $94(24 \%)$ & $22(12 \%)$ & \\
\hline \multicolumn{5}{|l|}{ Age (years) } \\
\hline Female & $57.5(6.8)$ & $48.8(7.1))$ & $48.8(6.7)$ & \\
\hline Male & $47.8(8.1)$ & $49.5(7.5)$ & $51.5(7.2)$ & \\
\hline Clinical Assessment & $\begin{array}{l}\text { No Pain } \\
(n=47)\end{array}$ & $\begin{array}{c}\text { Regional pain } \\
\quad(n=15 I)\end{array}$ & $\begin{array}{l}\text { Widespread pain } \\
\quad(n=87)\end{array}$ & $\begin{array}{c}\text { Fibromyalgia } \\
\qquad(n=19)\end{array}$ \\
\hline \multicolumn{5}{|l|}{ Gender } \\
\hline Female & $30(64 \%)$ & II 17 (77\%) & 78 (90\%) & $19(100 \%)$ \\
\hline Male & 17 (36\%) & $34(23 \%)$ & $9(10 \%)$ & $0(0 \%)$ \\
\hline \multicolumn{5}{|l|}{ Age (years) (Mean/SD) } \\
\hline Female & $47.4(5.6)$ & $49.6(6.9)$ & $49.1(6.8)$ & $50.8(6.5)$ \\
\hline Male & $50.8(7.4)$ & $51.6(6.0)$ & $51.4(7.3)$ & - \\
\hline \multicolumn{5}{|l|}{ BMI* $\left(\mathrm{kg} / \mathrm{m}^{2}\right)($ Mean $/ \mathrm{SD})$} \\
\hline Female & $28.1(5.9)$ & $27.8(6.1)$ & $27.4(4.9)$ & $27.4(4.5)$ \\
\hline Male & $27.5(4.4)$ & $27.0(3.5)$ & $27.1(2.5)$ & - \\
\hline Total & $27.9(5.3)$ & $27.6(5.5)$ & $27.3(6.8)$ & $27.4(4.5)$ \\
\hline \multicolumn{5}{|l|}{ Occupation } \\
\hline Retired & $2(4.3 \%)$ & $24(\mid 5.9 \%)$ & $12(13.7 \%)$ & $4(21.1 \%)$ \\
\hline Unemployed & $2(2.3 \%)$ & $6(4.0 \%)$ & $4(8.5 \%)$ & I (5.3\%) \\
\hline Household work & $24(44.2 \%)$ & $66(43.7 \%)$ & $44(56.4 \%)$ & $10(52.7 \%)$ \\
\hline People who work mainly standing up** & $17(35.1 \%)$ & $4 \mathrm{I}(27.2 \%)$ & $21(24.1 \%)$ & $4(21.1 \%)$ \\
\hline People who work mainly sitting down $* * *$ & $6(12.8 \%)$ & $12(7.9 \%)$ & $6(6.9 \%)$ & $0(0.0 \%)$ \\
\hline
\end{tabular}

** For example: cooker, bodyguard, carpenter etc. *** For example: driver (bus, taxi), secretary etc. 
Table 2: Fibromyalgia symptoms assessed by the Fibromyalgia Impact Questionnaire (FIQ) and by the Visual Analogue Scale (VAS).

\begin{tabular}{|c|c|c|c|c|c|}
\hline \multirow[t]{2}{*}{ SYMPTOMS } & $\begin{array}{l}\text { No Pain } \\
(n=47)\end{array}$ & $\begin{array}{l}\text { Regional Pain } \\
(n=15 I)\end{array}$ & $\begin{array}{l}\text { Widespread Pain } \\
\quad(n=87)\end{array}$ & $\begin{array}{c}\text { Fibromyalgia } \\
\quad(n=19)\end{array}$ & \multirow[t]{2}{*}{ P value } \\
\hline & Mean (SD) & Mean (SD) & Mean (SD) & Mean (SD) & \\
\hline Pain VAS & $2.2(3.0)$ & $5.1(3.2)$ & $6.1(2.9)$ & $7.9(1.8)$ & $<0.001 *$ \\
\hline \multicolumn{6}{|l|}{ FIQ } \\
\hline Physical Function & $9.3(5.9)$ & II.2(5.8) & $10.8(5.4)$ & $12.4(7.7)$ & 0.12 \\
\hline Feeling Well & $4.8(2.7)^{\mathrm{a}, \mathrm{c}}$ & $3.7(2.8)^{\mathrm{b}}$ & $2.5(2.5)^{b, c}$ & $2.0(2.6)^{\mathrm{a}}$ & $<0.00 I^{*}$ \\
\hline Work Missed & $0.0(0.1)$ & $0.2(0.9)$ & $0.1(0.6)$ & $0.0(0.0)$ & 0.26 \\
\hline Job Ability (VAS) & $2.4(2.8)^{\mathrm{a}}$ & $5.1(3.1)^{b}$ & $5.7(3.0)^{\mathrm{b}}$ & $6.6(2.8)^{\mathrm{a}}$ & $<0.001 *$ \\
\hline Pain (VAS) & $2.2(2.8)^{a}$ & $5.7(3.0)^{b}$ & $6.3(2.5)^{\mathrm{b}}$ & $7.7(1.8)^{a}$ & $<0.00 I^{*}$ \\
\hline Fatigue (VAS) & $3.1(3.1)^{a, c, d}$ & $5.7(2.9)^{\mathrm{b}, \mathrm{d}}$ & $6.9(2.5)^{b, c}$ & $7.5(2.3)^{\mathrm{a}}$ & $<0.00 I^{*}$ \\
\hline Morning Tiredness (VAS) & $2.3(2.3)^{b, d, e}$ & $4.1(3.1)^{a, c, e}$ & $5.8(2.8)^{\mathrm{c}, \mathrm{d}}$ & $6.6(3.0)^{\mathrm{a}, \mathrm{b}}$ & $<0.001 *$ \\
\hline Stiffness (VAS) & I.8 $(2.3)^{b, c, d}$ & $5.3(7.9)^{\mathrm{a}, \mathrm{d}}$ & $5.9(3.0)^{c}$ & $7.5(2.5)^{\mathrm{a}, \mathrm{b}}$ & $<0.00 I^{*}$ \\
\hline Anxiety (VAS) & $4.3(3.3)^{a, c, d}$ & $6.3(2.9)^{\mathrm{b}, \mathrm{d}}$ & $7.6(2.3)^{b, c}$ & $7.6(2.5)^{\mathrm{a}}$ & $<0.00 I^{*}$ \\
\hline Depression (VAS) & $3.4(3.1)^{\mathrm{a}, \mathrm{b}, \mathrm{c}}$ & $5.4(3.2)^{c}$ & $6.2(2.8)^{\mathrm{b}}$ & $7.0(2.5)^{\mathrm{a}}$ & $<0.001 *$ \\
\hline
\end{tabular}

* statistically different for $\alpha=0,05$, Kruskal Wallis Anova

$\mathrm{a}, \mathrm{b}, \mathrm{c}, \mathrm{d}, \mathrm{e}$ in pairs identify which groups are statistically different between, Multiple Comparison Test

in studies that enrolled other age categories, such as 18 or 20 and 70 or 80 years old $[1,4,8,13]$. Indeed, studies consistently show that FM is more common in middle-aged individuals (Table 3) and is less prevalence in the youngest and the elderly. Carmona et al. 2001 [1] found prevalence of FM being $1.6 \%$ from $30-39$ years, increasing to $4.9 \%$ in the forth decade and then decreasing to $3.7 \%$ between 50 and 59 years old. Senna et al., in a study conducted in Brazil found the prevalence of 2.5\% [4] However, in those of 35-54 years old, the prevalence was 5.5\% $[4.2 \% ; 6.8 \%]$, numerically higher than ours $(4.4 \%, 95 \%$ $\mathrm{CI}=2.6 \%-6.3 \%)$.

Although the prevalence of FM in our casuistic was very similar to what had been found in other studies, we found a higher prevalence of widespread chronic pain $(24 \%$, $95 \% \mathrm{CI}=21-27 \%$ ). Croft et al. [30] reported prevalence of $11.2 \%$, later confirmed by Storozhenko et al. [31]. This discrepancy may be due to the fact we enrolled a high-risk population for chronic pain. Both middle age [32] and female gender are known risk factors for chronic pain [33-
35], determined by biological [36] and social factors $[32,37,38]$. Increased weight is also a risk factor for pain, especially in women [32]. Furthermore, low-income individuals are more likely to work in manual functions, which may also facilitate injuries and pain. Wijnhoven et al. [39] related that non-paid work (e.g. household work) is per se a risk factor for pain $[33,36]$. Other studies report an inverse association between education and chronic pain $[33,36]$. Accordingly, our sample should be considered of high risk for widespread chronic pain (as shown in Table 1).

The last assumption is supported by the fact that several studies showed an inverse relation between presence of musculoskeletal symptoms and socioeconomic status [40]. However, of interest is that these factors did not determine a higher prevalence of FM in our study. Another factor explaining the high prevalence of widespread chronic pain was the screening interview being conducted over the telephone, forcing reliance on selfreport.

Table 3: Fibromyalgia prevalence in literature in populations from 30 and 59 years.

\begin{tabular}{|c|c|c|c|c|c|c|c|}
\hline \multirow[t]{2}{*}{ Authors } & \multirow[t]{2}{*}{ gender } & \multicolumn{6}{|c|}{ Prevalence for age classes (years) } \\
\hline & & $30-39$ & $35-44$ & $35-54$ & $45-54$ & $40-49$ & $50-59$ \\
\hline Carmona et al.[I] & Both & $1.6 \%$ & - & - & - & $4.6 \%$ & $5.7 \%$ \\
\hline Senna et al.[4] & Both & - & - & $5.5 \%$ & - & - & - \\
\hline Topbas et al.[29] & Female & $3.5 \%$ & - & - & - & $5.0 \%$ & $10.1 \%$ \\
\hline Wolfe et al.[8] & Female & $2.0 \%$ & - & - & - & $3.4 \%$ & $5.6 \%$ \\
\hline White et al.[13] & Female & - & $5.5 \%$ & - & $6.6 \%$ & - & - \\
\hline
\end{tabular}


We also assessed the main symptoms of FM in the population. Although not considered in the ACR criteria, they define the essence of the syndrome $[41,42]$ and add to its disability [13] and negative impact on quality of life [14]. We used the FIQ to assess the impact of FM symptoms in individuals not fulfilling de ACR criteria. Some symptoms were common in the other groups as well. As compared to individuals with NP, there were significant differences for all FIQ items, except for "physical function" and "work missed. However, the multiple variances analysis showed that, for the majority of FIQ items, NP and RP were similar and statistically different than the groups WP and FM (which, in turn, where not different).

Accordingly, we notice that although WP and FM have different criteria and definitions, the intensity of the symptoms is similar. It may be that individuals with WP, due to the physical and emotional aspects of pain [43], decrease physical and social activities and become more sedentary [44]. Eventually this may predispose to anxiety, depression and tiredness which, according to Croft et al. [30], may then predispose to FM.

Alternative, it may be that many individuals with WP have unclassified FM. As with FM, individuals with WP have chronic pain in different regions of the body. However, they have less than 11 tender points. It has been suggested that experienced rheumatologists often diagnose WP as FM, even in the absence of tender points [45]. Indeed, recent discussions question whether the ACR Criteria adequately capture the essence of FM. Symptoms perhaps could be included in the diagnosis again $[41,42]$ as had been used by Smythe \& Modollfsky [46].

Being so prevalent in the population assisted by the primary care public system, WP and FM are certainly of economic importance, suggesting that the health professionals should be careful in assessing these disorders. Future studies should be developed to assess the adequacy of the ACR criteria in the primary care.

Our study has limitations. Our sample was formed among people registered in the Public Health Care System of Embu, and the data may not be extrapolated. Several biases may exist in the screening interview including lack of telephone or inability to be contacted. The screening survey was established based on methodological and economical feasibility. Some of these biases were at least partially addressed by the Bayesian Analyses. Nonetheless, we suggest that future studies addressing the low-income population account for inherent problems of dealing with this stratum, including education limitations (difficulties in understanding certain questions or demands, need for cross-cultural adaptation of the instruments, etc). Finally, it may be that the personal assessments should be done in the household of the participants, to mitigate economic barriers (e.g. lack of money for transportation, need to work on weekends). Nonetheless, our findings should not be discrepant to what happens in similar cities.

\section{Conclusion}

Our findings point for the importance of FM to the public health system, and highlight the need of preparing public policies to prepare the system to the demand posed by $\mathrm{FM}$, and also to provide adequate care aiming to improve the daily life activities and the quality of life, as recently suggested by Blyth [47]. These policies are especially important for people of low income, who depend on the government health care system. Because classification of FM was done using the ACR Criteria proposed in 1990, future studies are necessary to discuss the better criteria to account for the syndrome complexity.

\section{Competing interests}

The authors declare that they have no competing interests.

\section{Authors' contributions}

AA took part of acquisition and interpretation of data and of manuscript writing. ALC, SDC and CEC made substantial contributions for acquisition and interpretation of data. JFS participated in the acquisition and interpretation of data, in drafting the manuscript and in revising it critically. $\mathrm{CAB}$ conducted the Baeysian analyses and made essential contributions for interpretation of data. APM is responsible for the conception and design of the study, has participated in acquisition of data and revised the manuscript critically. All authors read and approved the final manuscript.

\section{Acknowledgements}

This work was supported by Fundação de Amparo a Pesquisa do Estado de São Paulo (FAPESP) - Foundation for the Support of São Paulo State - and Conselho Nacional de Pesquisa e Desenvolvimento (CNPq) - National Council of Research and Development.

The authors acknowledge the administration of the city of Embu for allowing the study using the structure of the Unified Health System. We specially thank all volunteers participating in the study.

\section{References}

I. Carmona L, Ballina J, Gabriel R, Laffon A, EPISER study Group: The burden of musculoskeletal diseases in the general population of Spain: results from a national survey. Ann Rheum Dis 200I, 60:1040-1045.

2. Haq AS, Darmawan J, Islam MN, Uddin MZ, Das BB, Rahman F, Chowdhury MA, Alam MN, Mahmud TA, Chowdhury MR, Tahir M: Prevalence of rheumatic diseases and associated outcomes in rural and urban communities in Bangladesh: a COPCORD study. J Rheumatol 2005, 32:348-53.

3. Wolfe F, Cathey MA: Prevalence of primary and secondary fibrositis. J Rheumatol 1983, 10:965-8.

4. Senna ER, De Barros AL, Silva EO, Costa IF, Pereira LV, Ciconelli RM, Ferraz MB: Prevelence of rheumatic diseases in Brazil: a study using the COPCORD approach. J Rheumatol 2004, 3 I:594-7.

5. Cardiel $\mathrm{MH}$, Rojas-Serrano J: Community based study to estimate prevalence, burden of illness and help seeking behavior 
in rheumatic diseases in Mexico City. A COPCORD study. Clin Exp Rheumatol 2002, 20:617-24.

6. Goldenberg DL, Simms RW, Geiger A, Komaroff AL: High frequency of fibromyalgia in patients with chronic fatigue seen in a primary care practice. Arthritis Rheum 1990, 33:38I-387.

7. Cavalcante $A B$, Sauer JF, Chalot SD, Assumpção A, Matsutani LA, Lage LV, Marques AP: A prevalência de fibromialgia: uma revisão de literatura. Rev Bras Reumatol 2006, 46:40-48.

8. Wolfe F, Ross K, Anderson J, Russell J, Herbert L: The prevalence and characteristics of Fibromyalgia in the general population. Arthritis Rheum 1995, 38:19-28.

9. Robinson RL, Birnbaum HG, Morley MA, Sisitsky T, Greenberg PE, Claxton AJ: Economic cost and epidemiological characteristics of patients with fibromyalgia claims. J Rheumatol 2003, 30:13|8-25.

10. Boonen A, Heuvel R van den, van Tubergen A, Goznes M, Severens $J L$, Heijde $D$ van der, Linden van der: Large differences in cost of illness and wellbeing between patients with fibromyalgia, chronic low back pain, or ankylosing spondylitis. Ann Rheum Dis 2005, 65:396-402.

II. Hawley DJ, Wolfe F: Pain, disability, and pain/disability relationships in seven rheumatic disorders: a study of 1.522 patients. I Rheumatol 1991, 18:1552-1557.

12. Henriksson CM: Long-term effects of fibromyalgia on everyday life. A study of 56 patients. Scand J Rheumatol I994, 23:36-4I.

13. White KP, Speechley M, Harth M, Ostbye T: Comparing selfreported function and work disability in 100 community cases of fibromyalgia syndrome versus controls in London, Ontario: The London Fibromyalgia Epidemiology Study. Arthritis Rheum 1999, 42:76-83.

14. Martinez JE, Ferraz MB, Sato El, Atra E: Fibromyalgia versus rheumatoid arthritis: a longitudinal comparison of the quality of life. J Rheumatol 1995, 22:270-274.

15. Martinez JE, Atra E, Ferraz MB, Silva PSB: Fibromialgia: aspectos clínicos e sócio-econômicos. Rev Bras Reumatol 1992, 32:225-30.

16. IBGE: [http://www.ibge.gov.br/cidadesat/topwindow.htm?I].

17. Wolfe F, Smythe HA, Yunus MB, Bennett RM, Bombardier C, Goldenberg DL, et al:: The American College of Rheumatology 1990 Criteria for the classification of fibromyalgia. Report of the Multicenter Criteria Commitee. Arthritis Rheum 1990 33:160-72

18. Fischer AA: Pressure algometry over normal muscle. Standard values, validity and reproducibility of pressure threshold. Pain 1987, 30:115-26.

19. Okifuji A, Turk DC, Sinclair JD, Starz TW, Marcus DA: A standardized manual tender point survey. I Development and determination of a threshold point for the identification of positive tender points in fibromyalgia syndrome. J Rheumatol 1997, 24:377-83.

20. Marques AP, Ferreira EA, Matsutani LA, Pereira CA, Assumpção A: Quantifying pain threshold and quality of life of fibromyalgia patients. Clin Rheumatol 2005, 24:266-7I.

21. Harden N, Revivo G, Song S, Nampiaparampil D, Golden G, Kirincic $M$, et al:: A Critical Analysis of the Tender Points in Fibromyalgia. Pain Med 2007, 2: 147-156.

22. Tunks E, McCain GA, Hart LE, et al.: The reliability of examination for tenderness in patients with myofascial pain, chronic fibromyalgia and controls. I Rheumatol 1995, 22:944-52.

23. Burckhardt CS, Clark SR, Bennett RM: The fibromyalgia impact questionnarie: Development end Validation. J Rheumatol I99I, I 8:728-33.

24. Marques AP, Santos AMB, Assumpção A, Matsutani LA, Lage LV Pereira $C A B$ : Validação da versão Brasileira do Fibromyalgia Impact Questionnaire (FIQ). Rev Bras Reumatol 2006, 24:24-3I.

25. Goldstein M: Subjective Bayesian Analysis: Principles and Practice. Bayesian Analysis 2006, I:403-20.

26. Prescott E, Kjøller M, Jacobsen S, Bülow PM, Danneskiold-Samsøe B, Kamper-Jørgensen F: Fibromyalgia in the adult Danish population: I. A prevalence study. Scand J Rheumatol 1993, 22:233-7.

27. Forseth KO, Gran JT: The prevalence of fibromyalgia among women aged 20-49 years in Arendal, Norway. Scand J Rheumatol 1992, 2 1:74-8.

28. Schochat $\mathrm{T}$, Raspe $\mathrm{H}$ : Elements of fibromyalgia in an open population. Rheumatology (Oxford) 2003, 42:829-35.
29. Topbas M, Cakirbay H, Gulec H, Akgol E, Ak I, Can G: The prevalence of fibromyalgia in women aged 20-64 in Turkey. Scand J Rheumatol 2005, 34: I 40-4.

30. Croft P, Rigby AS, Boswell R, Schollum J, Silman A: The prevalence of chronic widespread pain in the general population. J Rheumatol 1993, 20:710-3.

31. Storozhenko ON, Lesniak OM, Macfarlane GJ, McBeth J: The prevalence of chronic generalized pain and its relationship to demographic characteristics and mental status. Klin Med (Mosk) 2004, 82:48-52

32. Saastamoinen $P$, Leino-Arjas $P$, Laaksonen $M$, Lahelma E: Socio-economic differences in the prevalence of acute, chronic and disabling chronic pain among ageing employees. Pain 2005, I | 4:364-7|.

33. Bergman S, Herrström P, Högström K, Petersson IF, Svensson B, Jacobsson LT: Chronic musculoskeletal pain, prevalence rates, and sociodemographic associations in Swedish population study. I Rheumatol 200I, 28: I369-77.

34. Rustoen T, Wahl AK, Hanestad BR, Lerdal A, Paul S, Miaskowski C: Prevalence and characteristics of chronic pain in the general Norwegian population. Eur J Pain 2004, 8:555-65.

35. Gerdle B, Bjork J, Coster L, Henriksson KG, Henriksson C, Bengtsson $A$ : Prevalence of widespread pain and associations with work status: a population study. BMC Musculoskeletal Disorders 2008, 9:102

36. Blyth FM, March LM, Brnabic AJM, Jorm LR, Williamson, Cousins MJ: Chronic pain in Australia: a prevalence study. Pain 200I, 89: $127-34$.

37. Wiesenfeld-Hallin Z: Sex Differences in Pain Perception. Gender Medicine 2005, 2: 137-45.

38. Denton M, Prus S, Walters V: Gender differences in health: a Canadian study of the psychosocial, structural and behavioural determinants of health. Soc Sci Med 2004, 58:2585-600.

39. Wijnhoven HAH, de Vet HCW, H. Picavet SJ: Explaining sex differences in chronic musculoskeletal pain in a general population. Pain 2006, 124:158-66.

40. Brekke M, Hjortdahl P, Kvien TK: Severity of musculoskeletal pain: relations to socioeconomic inequality. Soc Sci Med 2002, 54:221-228

4I. Crofford LJ, Clauw DJ: Fibromyalgia: Where are we a decade after the American College of Rheumatology Classification Criteria we developed? Arthritis Rheum 2002, 46: II36-38.

42. Martinez JE: Fibromialgia: o desafio do diagnóstico correto. Rev Bras Reumatol 2006, 46:2.

43. Melzack R, Wall PD: Pain mechanisms: a new theory. Science 1965, 150:97|-9.

44. Grotle M, Vøllestad NK, Veierød MB, Brox Jl: Fear-avoidance beliefs and distress in relation to disability in acute and chronic low back pain. Pain 2004, I I 2:343-352.

45. Katz RS, Wolfe F, Michaud K: Fibromyalgia Diagnosis: a comparison of clinical, survey, and American College of Rheumatology criteria. Arthritis Rheum 2006, 54:169-76.

46. Smythe HA, Moldofsky H: Two contributions to understanding of the "fibrositis" syndrome. Bull Rheum Dis 1977, 28:928-93I.

47. Blyth FM: Chronic pain - is it a public health problem? Pain 2008, 173:465-466.

\section{Pre-publication history}

The pre-publication history for this paper can be accessed here:

\section{http://www.biomedcentral.com/1471-2474/10/64/pre}

pub 